\title{
Automated control of Cocoa post-harvest and transformation process to obtain high-quality beans
}

\author{
Juan de Jesús Umbarila*, Diego A. Rivera ${ }^{\dagger}$, Specialists in instrumentation and industrial control, \\ Walter Naranjo Lourido ${ }^{\ddagger}$, Ph.D. in Mechanical Engineering, and \\ Javier E. Martínez ${ }^{\S}$, Master in Educative Technology. \\ ${ }^{* \dagger}$ Faculty of Basic Science and Engineering, Universidad de Los Llanos, Colombia. \\ ${ }^{\ddagger}$ Department of Mechanical Engineering, Universidad de Los Andes, Colombia.

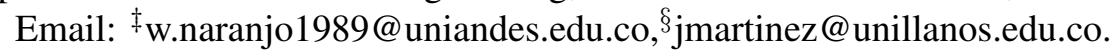

\begin{abstract}
This paper develops a method to intervene in the Cocoa post-harvest process (fermentation and drying) to guarantee a high quality of the bean. For this intervention, it is automated controlled the turning and duration of the fermentation and drying of the cocoa beans. A Cocoa with an inadequate post-harvest and transformation process has unpleasant taste characteristics such as astringency and high acidity $(\mathrm{pH}<5)$, that can not be removed in a normal process. These flavors are associated with a poor fermentation and others sowed materials, which directly affects the sensory quality of the grain. In this way, a control and monitoring system is developed. This system intervenes on the most influential $v$ ariables $f$ or high-quality production, to guarantee a better fermentation (with $5.5<\mathrm{pH}<6$ ) and drying processes. The system has an HMI for adjustments and visualization of variables in real-time.
\end{abstract}

Index Terms-Cocoa, post-harvest, fermentation, drying, automatic control, quality indicators, agricultural systems, sustainability.

\section{INTRODUCTION}

$\mathbf{T}$ He world production of Cocoa beans is focused in tropical countries, mainly located in Africa and America continents. According to the World Cocoa Foundation, the number of growers is around five and six million, which produces around 4,3 million tons. For 2015, the International Cocoa Organization (ICCO) reported that the countries with the highest world production were Ivory Coast (1,73 million tons - Mt), Ghana (0,92 Mt), Indonesia (420 thousand tons - kt), and Nigeria $(240 \mathrm{kt})$. In America are stand out Brazil $(210 \mathrm{kt})$, and Ecuador (191 kt).

For the Colombian case, the Cocoa production in 2014 was concentrated mainly in the Santander region (19 kt), followed by Arauca (5,5 kt), Antioquia (3,5 kt) and Huila (3,3 kt) regions. Colombia commercializes a low volume of premium cocoa type; almost all its production is sold as a normal type according to Colombian technical standards NTC 1252 - 2003.

According to experts, the final quality of a fine cocoa bean depends on fours factor: (1) Cocoa genetics, around 50\%; (2) post-harvest or benefit process, $20 \%$, these mean fermentation and drying process; (3) transformation process (toasted and shell), 25\%; and (4) soil and climate characteristics, $5 \%$. This means that controlled both processes are possible to

Digital Object Identifier (DOI):

http://dx.doi.org/10.18687/LACCEI2020.1.1.544

ISBN: 978-958-52071-4-1 ISSN: 2414-6390 improve the bean quality around $45 \%$, which would allow the exportation of this product.

\section{FRAMEWORK}

\section{A. Cocoa overview}

Theobroma cacao is the Greek name for the cocoa tree, and its fruit is commonly called Cocoa cob(1). This cob is an ovoid berry approximately $30 \times 10 \mathrm{~cm}$ in large and diameter, with grooves along with a weight between 0,2 to $1 \mathrm{~kg}$. The cob color is yellow, red, orange, green or brown, depending on the genotype. Inside, it contains from 20 to 40 seeds, covered by a white mucilaginous pulp, rich in sugars with an acid taste, which fresh cocoa or recently extracted is called cocoa in drool, [2].

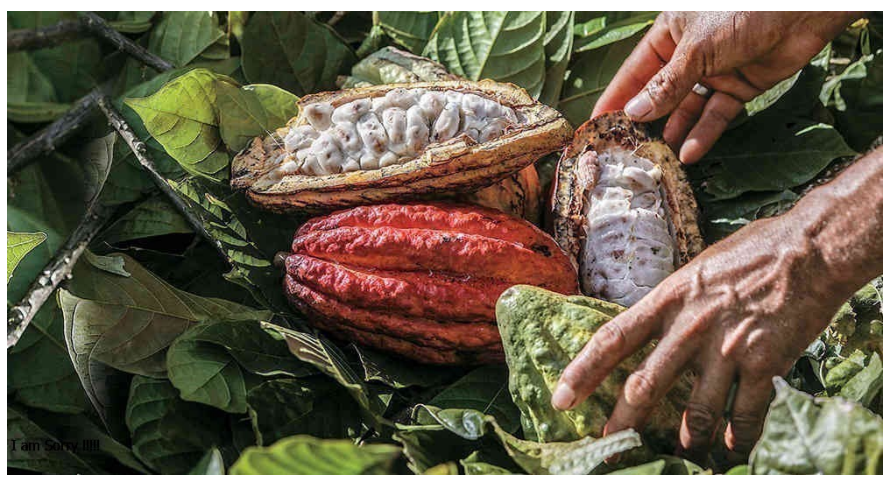

Fig. 1. Colombian Cocoa. Source: Fedecacao (Federación Nacional de Cacaoteros)

Table II-A shows the Physical-chemical parameters and other parameters that are established by NTC 1252 to determine the bean quality. Among these parameters are the bean index, which determines the average bean weight in grams; and the cub index that defines how many cubs are required to obtain a kilogram of dry Cocoa, [2].

\section{FERMENTATION OF COCOA BEANS}

This process is the combination of microbial and enzymatic reactions that occur inside the pulp. The quantitative and qualitative nature of these reactions is moderated by several factors that include: the type of cultivation of the cocoa plant, 
TABLE I

PHYSICAL-CHEMICAL PARAMETERS OF COCOA BEANS, USED BY THE PROCESSING INDUSTRIES IN COLOMBIA FOR CLASSIFICATION.

\begin{tabular}{l|l|l|l} 
Description & Low & Normal & High \\
\hline Bean index & $<1.05$ & 1.05 a 1.2 & $>1.2$ \\
Humidity percentage & 6 a 6,5 & 7 a 8 & $>8$ \\
Average of fat & $<52$ & 52 a 55 & $>55$ \\
pH & $<5,0$ & 5,0 a 5,5 & $>5,5$ \\
Cob index & $<15$ & 16 a 20 & $>21$ \\
Flavor & Bitter & Acid & Normal
\end{tabular}

the maturation stage of the ears, the local natural microbiota of the region where the crop grows up, the climatic conditions, also each farmer practices carries out during the process, [2].

Two significative phenomenons that occur during fermentation, these are a microbial activity in the mucilaginous pulp and complex biochemical reactions inside the cotyledons. The microbial activity phenomenon transforms the mucilaginous pulp into alcohol and acids, releases heat. On the other side, the biochemical reactions inside the cotyledons, it is initiated by the diffusion of pulp metabolism products.

The cocoa fermentation is carried out by two sequential phases, which are anaerobic and aerobic. In both phases are involved different groups of yeasts, lactic acid bacterias $(\mathrm{LAB})$ and, acetic acid bacterias (AAB) that break down the mucilaginous pulp composition.

In the first phase, the anaerobic phase, the mucilage sugars are transformed into ethyl alcohol and, later, in lactic acid due to the intervention of yeasts and LAB. This yeast proliferates because of the absence of oxygen, which increases in temperature of the fermentation dough between 30 to $35^{\circ} \mathrm{C}$. Also, the yeast acidifies the dough, which generates an onset in the breakdown of pulp cells during the first 24 hours. Yeasts use fermentable pulp sugars to produce ethanol and carbon dioxide. During this process are secreted pectinolytic enzymes, which help solubilize the pulp. After twenty-four hours, the yeast population begins to slowly decrease, favoring the growth of $\mathrm{LAB}$, which reaches its peak after thirty-six hours after fermentation begins. The LAB decomposes the glucose to lactic acid above all [2].

In the second phase, the aerobic phase begins with the aeration of the grains after forty-eight hours of the fermentation process. Once the oxygen is introduced to the dough, the $\mathrm{LAB}$ population decreases creating favorable conditions for AAB growth. These bacterias are responsible for the oxidation of ethanol, creating acetic acid and then carbon dioxide and water. All these exothermic reactions produce a rise in the mass temperature to $50^{\circ} \mathrm{C}$. As a result, the fermentation causes the diffusion of alcohol and acetic acid in the grain, and the germination inhibition. This is how a series of biochemical reactions, divided into two phases, have triggered that lead to the formation of flavor precursors.

\section{A. Fermentation methods}

Nowadays, the fermentation methods commonly used in the Cocoa industries, according to [2], are the following:

- Fermentation in piles: it creates cocoa almonds piles on wooden or a banana leaf, draining the leached easily. Generally, these piles are covered with banana leaves or jute bags to provide better dough temperature conditions.

- Fermentation in simple wooden drawers: the drawers are constructed with moisture-resistant wood planks, such as cedar or walnut, and other soft-type woods free of resins and do not give off foreign substances that interfere with the cocoa quality. Each drawer and its cover uses banana leaves or jute bags as material. See Fig. 2 taken from [8].

- Fermentation in a rotary drum: they are horizontal wooden cylinders, completely closed with an axis in the center, which allows aerating the dough with a lever movement.

- Fermentation in a sack: the fermentation dough is introduced in polypropylene or jute sacks for 5 to 7 days. In this fermentation method, the dough is not aerated.

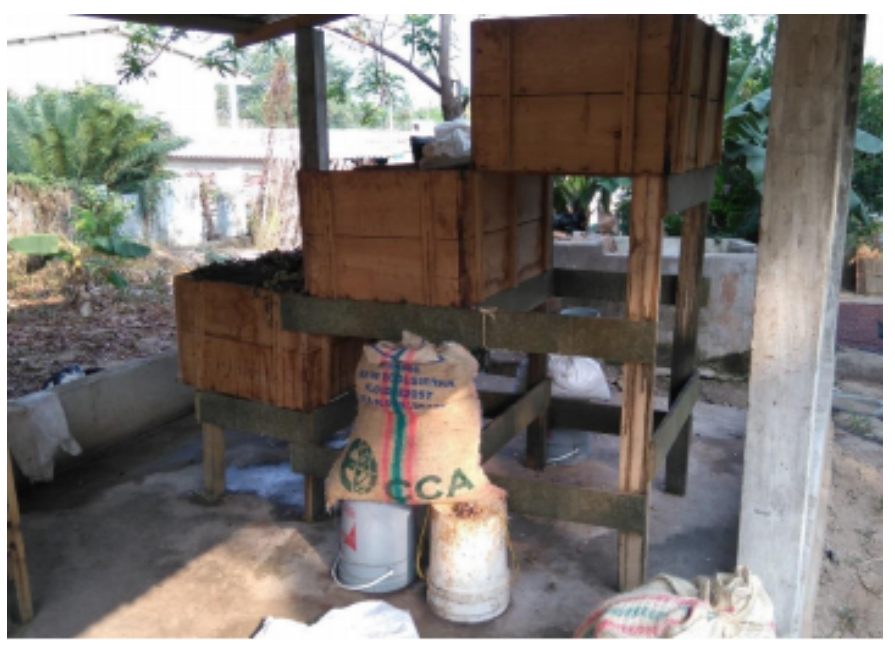

Fig. 2. Fermentation in simple wooden drawers. Source: William M. Paéz. Universidad de La Salle

Practices that are carried out during fermentation determines the physical-chemical characteristics of cocoa beans. One of these practices has a flip frequency of the cocoa grains, which as a high influence on good fermentation. The results show cocoa grains with high-grade physical attributes when the mass turns every 12 or 24 hours. However, during those flip frequencies, the total polyphenols concentration decreases as the antioxidant activity, [2].

\section{B. Drying}

The moisture content in fermented grains is around 55\%, but in order not to decrease the quality due to its storage, you must stop this process in 7\% according to [3]. Drying is 
TABLE II

LOSS OF RAW MATERIAL PER PROCESS

\begin{tabular}{l|c|c|c} 
Process & Time & $\%$ Lost & Waste Type \\
\hline Fermentation & 6 days & $30-50 \%$ & Liquid \\
Drying & 5 to 7 days & $10-15 \%$ & Mucilage
\end{tabular}

TABLE III

LOSS OF RAW MATERIAL

\begin{tabular}{l|c|c|c} 
Process & Initial Weight & Final Weight & Lost Weight \\
\hline Fermentation & $10 \mathrm{~kg}$ & $6 \mathrm{~kg}$ & $4 \mathrm{~kg}$ \\
Dried & $6 \mathrm{~kg}$ & $5.28 \mathrm{~kg}$ & 720 grams
\end{tabular}

carried out using sun dryers or artificial hot air dryers. During drying, the reactions initiated continue with the fermentation; its bitterness and astringency decrease the polyphenols, the almonds color changes, and the cotyledons turn brown or cinnamon color. For this reason, the moisture content should decrease slowly in a period of 5 to 7 days using the sun. With this, the oxidation reactions responsible for the flavor and aroma of cocoa are completed; otherwise, there is a risk of inactivating enzymes before the essential chemical changes been completed, which occur due to high temperatures $\left(>65^{\circ}\right.$ C), and low humidity. Also, a quick-drying induces the grain crushing, generating wrinkled cuticles that determine the cocoa product quality.

According to work developed by WM Paez Ramos, we can take as reference parameters the loss of raw material with purely handmade processes. See table III-B, and III-B as you can see in [8].

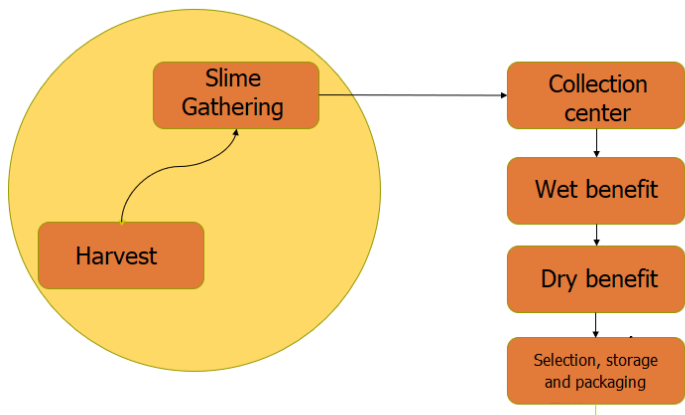

Commercialization

Fig. 3. Flowchart of the cocoa production process. Source: Authors.

\section{MATERIALS AND METHODS}

Fermentation and drying processes are designed according to quality requirements and the raw material used for project development. The system proposed has a local control panel, where all signals of the analytical measuring instruments can be visualized. The measuring instruments detect level, start/stop and emergency stop buttons, engine shutdown/ignition and opening/closing of On-Off control valves,
TABLE IV

DESCRIPTION OF MAIN COMPONENTS OF PROCCESS

\begin{tabular}{l|ccc} 
Parameters & TK-101 & TK-102 & TK-103 \\
\hline Diameter $[\mathrm{m}]$ & 1 & 0.3 & 2 \\
High $[\mathrm{m}]$ & 2 & 0.5 & 0.5 \\
Operating temperature $\left[{ }^{\circ} \mathrm{C}\right]$ & 55 & 55 & 55 \\
Design temperature $\left[{ }^{\circ} \mathrm{C}\right]$ & 80 & 80 & 80 \\
Pressure [atm] & 1 & 1 & 1
\end{tabular}

and manipulation of the respective control loops of the fermentation process. Each signal is brought to a PC via Ethernet TCP/IP communication for operator viewing.

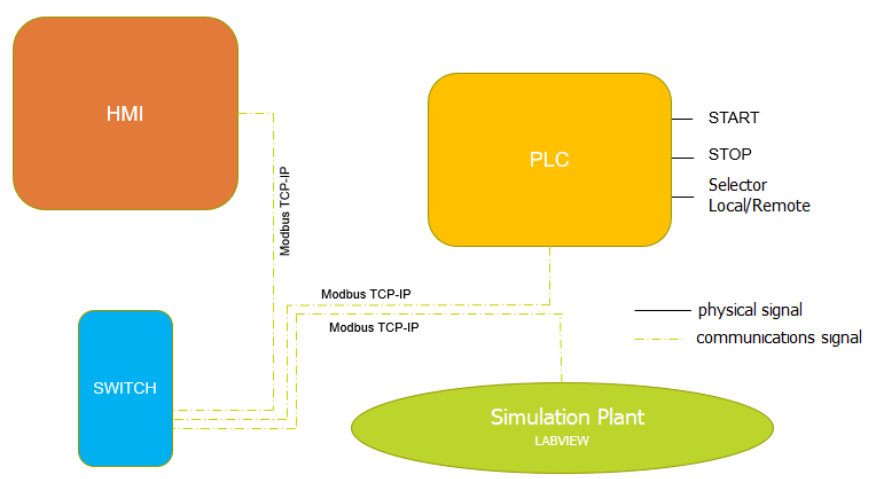

Fig. 4. Control and communications architecture

The flowchart of Fig. 5 shows the process steps and its main componets related as follows:

- TK-101 FERMENTATION HOP.

- TK-102 LIQUID COLLECTOR

- TK-103 DRY GRAIN COLLECTOR

Each before component was dimensioned in table IV.

\section{TRANSFORMATION PROCESS}

A brief description of the process is made next:

See P\&ID in Figure 5. See Control and communications architecture in the Fig. 4.

\section{A. Fermentation}

Cocoa stocks the process through the top cover of the TK-101 fermentation hopper. At this moment, the system state must be in "FILLED" mode, and the mixer screw installed inside the TK-101 would be stopped. Posteriorly, the discharge valve FV-101 and the FV-102 liquid evacuation valve located at the hopper base should be closed.

The process begins with a timer, which is activated to record the temperatures of the sensors TIT-101, TIT-102, TIT-103, TIT-104 A record of $\mathrm{pH}$ (AE-102) and relative humidity (AE-101) is also made. This data enters the PLC-001 controller, which employs the I-01 interlock that activates the M-101 motor for removing the product constantly to avoid 


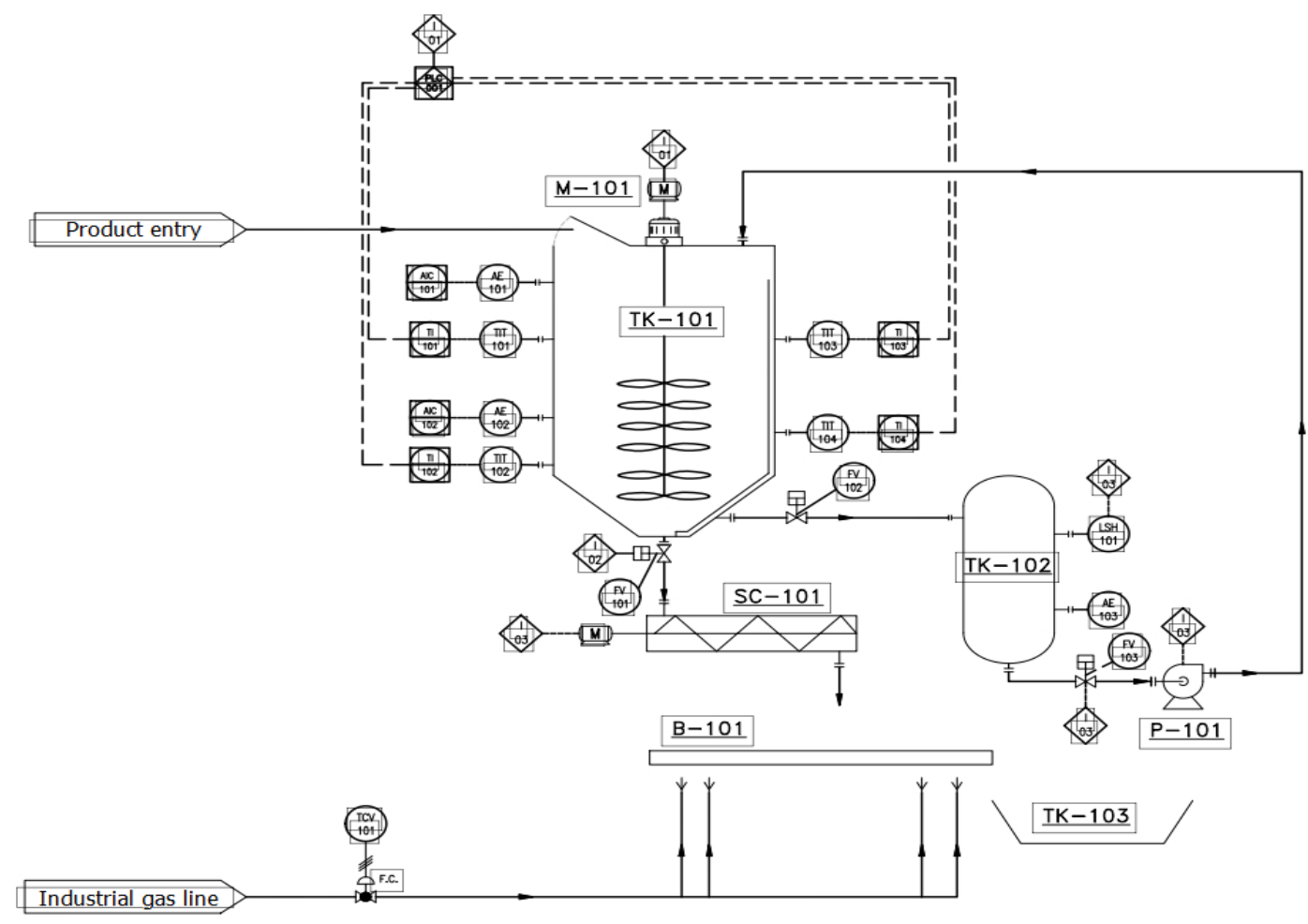

Fig. 5. P\&ID process of fermentation and benefit of cocoa. Source: Authors.

increasing of the temperature and $\mathrm{pH}$.

The liquid produced during the fermentation process is drained from the TK-101 hopper on one side by opening the FV-102 valve (On-Off drive) and deposited in the TK-102 fermentation tank. This liquid will accumulate until reaches the activation level of the LSH-101 high-level switch. This switch signal generates the I-03 interlock, with which the FV-103 valve is opened and the P-101 fermented recirculation pump is switched on, the fermented liquid re-enters the TK-101 hopper on the part superior to moisturize the grain and help maintain a stable $\mathrm{pH}$ level.

The fermentation process liquid is extracted from the TK-101 hopper, on one side, opening the FV-102 valve (On-Off drive) and deposited in the TK-102 fermentation tank. TK-102 will accumulate the liquid until reaching the activation level of the LSH-101 high-level switch. A switch signal generates the I-03 interlock, with which the FV-103 valve is opened and the P-101 fermented recirculation pump is switched on. Thus, the fermented liquid re-enters to TK-101 hopper, moisturizing the grain, and regulating the $\mathrm{pH}$ level.

When the timer becomes equal to a value set by the operator, the fermentation process will be terminated. The discharge valve FV-101 (on-off action) will open, a limit switch will indicate that the valve is $100 \%$, which open and will activate interlock I-02. At the same time, the I-02 will turn on the SC101 screw-type conveyor belt, while changing the direction of rotation of the mixer screw of the hopper TK-101. So, the screw to push the product towards the discharge valve FV-101. Once the TK-101 hopper is empty, the "FILLING" phase is enabled again to start the fermentation of Cocoa products.

\section{B. Drying}

The screw-type conveyor belt will take the product and bring it to the drying table B-101, which has four industrial gas burners controlled by the TCV-101 valve. This valve regulates the amount of gas supplied to guarantee a predefined temperature at the drying table that is monitored by four temperature sensors.

With the ignition of the industrial gas burners, the operator starts the drying timer. Once the drying is completed, the operator announcements to remove all dried products.

The HMI has a process screen in which you can see in real-time. Between these variables are the temperatures, $\mathrm{PH}$, relative humidity, state of the equipment (engines, valves), blocks for the configuration by the operator, and the elapsed times in each process.

\section{Construction And tests}

\section{A. Construccion}

For the construction of the control panel model, a $9 \mathrm{~mm}$ thick triplex sheet with a length of 120 x $60 \mathrm{~cm}$ was used. A perforation was made on the left side for the insertion of a Panel View Plus 1500 (HMI with a screen of 15 ”) as shown in Fig.6 and 7. At the bottom of the table and just 


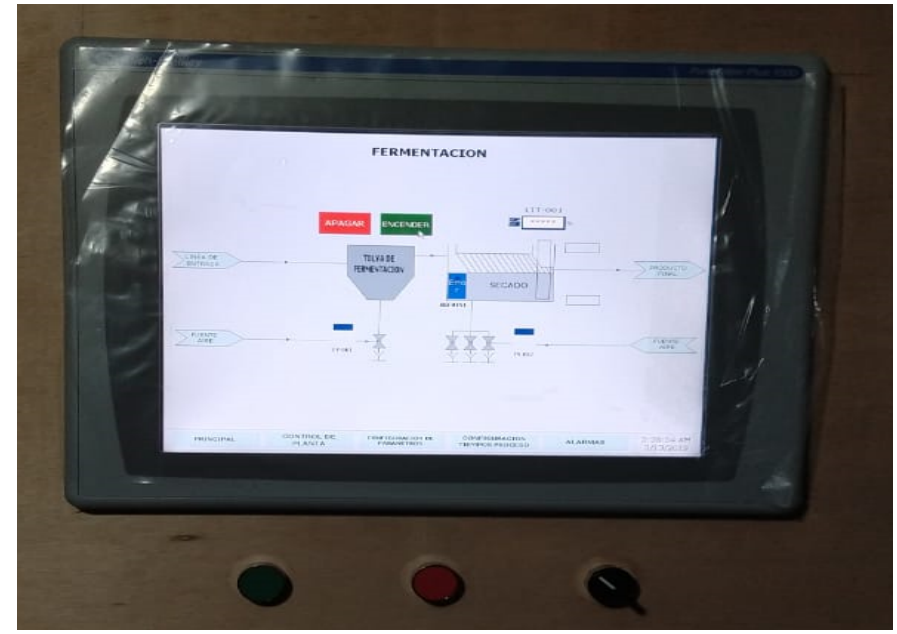

Fig. 6. HMI - Fermentation stage. Source: Authors.

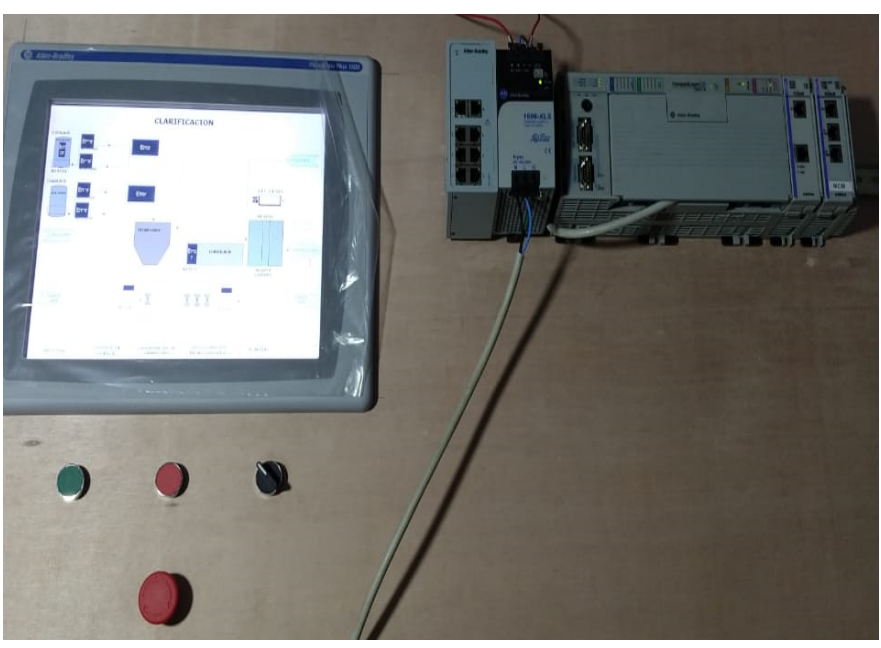

Fig. 7. Mounting \& communication with sensors. Source: Authors.

below the HMI, four holes are made where are installed: a NO (Start) button, an NC (Stop) button, a 2-position selector (manual/automatic) and an emergency stop button with mushroom retention.

On the right side, two $25 \mathrm{~mm}$ wide $\mathrm{x} 500 \mathrm{~mm}$ long DIN rail (Omega) rail units were fixed using wood screws. These rails are used for the quick anchor installation of the control units listed below:

- Stratix communications switch x 8 LAN ports

- 24V voltage source ref: 1606-XLS

- PLC Allen Bradley CompacLogix L23-QBFC1B

- Modbus TCP / IP communication card ref: Prosoft MVI69-MNET

- 16 AWG cable terminal set

We wired the internal components of the board with 16AWG cable. For this, we uses tubular pin terminals and heat shrinkable bushings for wiring identification. For cable organization, it installed 2 units of $20 \mathrm{~mm}$ grooved gutter.

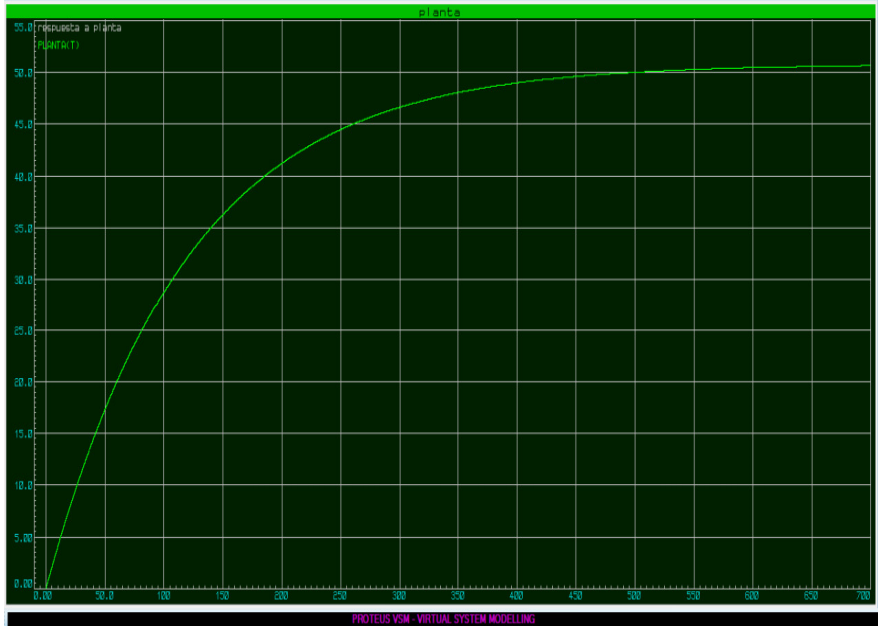

Fig. 8. Step response to temperature of fermentation. Source: Authors.

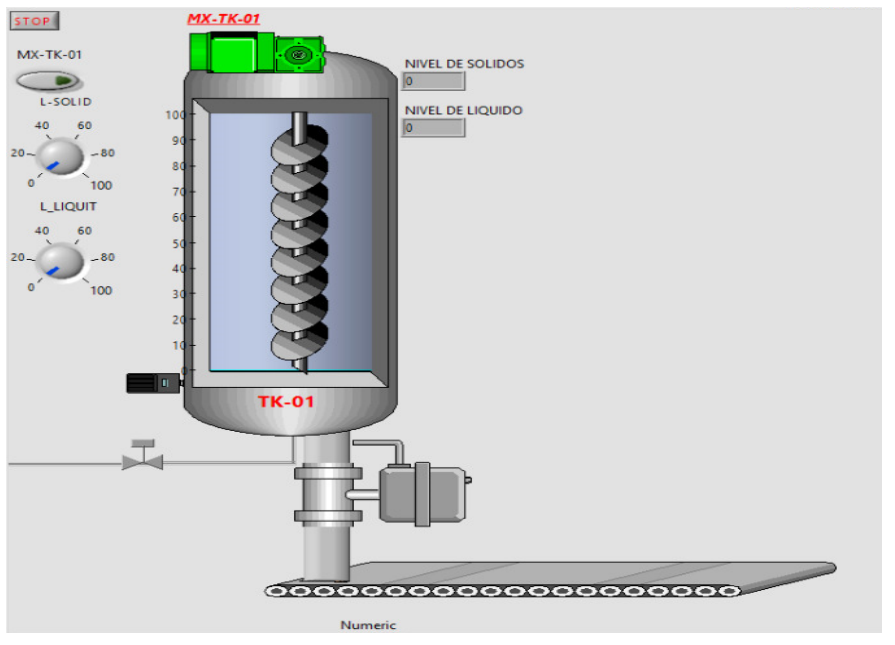

Fig. 9. Implementation of Labview GUI. Source: Authors.

\section{B. Tests}

- The Montecarlo tests performed corresponds to the communication between the PLC, HMI and operator console. It performs activation tests of PLC inputs and outputs, which were corroborated with the indication LEDs of each module.

- Additionally, the states and color changes in the process graphs displayed in the HMI are reviewed, in addition to the correct operation of the buttons (Start, Stop, Selector, Emergency stop) located on the front of the control panel.

- For the simulation, it uses Labview with TCP-IP protocol. This simulation allows us to create disturbances to guarantee a stable design, as shown in Fig. 9 and ??.

\section{Results \& CONCLUSIONS}

With the Montecarlo simulation of the control, employing the use of the PLC A L23-QBFC1B, the correct operation of the control algorithms for the drying and fermentation process of the cocoa, and its sensors, which uses a standard 
industrial communication signal of 4-20 mA. The algorithm for controlling the drying and fertilization time regulates the mucilage agitation speed to avoid changes in $\mathrm{pH}$.

As a pilot test, it was possible to check some operating parameters of the system, especially the temperature of the cocoa drying process. The system has a temperature response at $50^{\circ} \mathrm{C}$ at $700 \mathrm{rpm}$, which is equivalent to 40 minutes but it is required to keep that in a 56-hour course so that the dehydration of the seed is home-grown Fig. 8.

On the other hand, the developed user interface (GUI) has different levels of intervention, both manual and automatic, which allow the decision parameters of the process to be varied. It is important to note that these process parameters vary according to the humidity and height of the cocoa processing site. Additionally, this GUI allows for obtaining historical graphs of each sensor for studies and parameterization of the drying and fermentation process of cocoa to increase its quality.

As conclusions, the following three can be determined:

- It is important to highlight the need for simulation before starting the cocoa drying and fermentation system. Since the operating parameters of the plant change and are consistent with the geolocation of the cocoa crop and its processing system. In addition, the simulation verified the rapid response of the actuators to various operating conditions.

- The development of this fully automatic cocoa drying and fermentation process has not been implemented in a farm, at this time in Colombia. This type of process can guarantee the quality of the cocoa bean and the drying time. At same time, the fermentation is standardized to obtain premium cocoa for export.

- This work proposes a profound change around adding value to the cocoa production chain, allowing its transformation and raising its quality level, which would positively impact the economy of the producers of this grain.

\section{FUTURE WORK}

This work raises the need to carry out a standard experimental design for the determination of the operating parameters to obtain the best possible quality of processed cocoa. This process must be carried out under the operating conditions of the cocoa processing plant.

We expected to generate the large-scale implementation of these Automated control of Cocoa post-harvest and transformation process to obtain high-quality beans systems, for the grain growing regions of Colombia.

\section{REFERENCES}

[1] Federación NACIONAL DE CACAOTERos - FedecACAO https://www.dinero.com/edicion-impresa/pais/articulo/industria-delcacao-colombiano-produce-record/25161, Bogota, Colombia, 2017.

[2] LM. CARDONA tesis "Influencia del proceso de fermentación sobre las características de calidad del grano de cacao”,Universidad Nacional de Colombia, Sede Medellín, Colombia, 2016.

[3] Mahecha Rojas RAFAEL EMIlio Article "Efecto del secado y almacenaje sobre la calidad del cacao (Primera parte)”, Periódico de la Federación Nacional de Cacaoteros • Año 8 • No.23, Marzo - Abril 2015 Gobierno, productores e industria unidos por el cacao.

[4] AFOAKWA, E. O "Changes in acidification, sugars and mineral composition of cocoa pulp during fermentation of pulp pre-conditioned cocoa (Theobroma cacao) beans”,International Food Research Journal, 20(3): 1215-1222 (2013)

[5] Schwan, R. y FleEt, G. "Cocoa and Coffee Fermentations (first)”,London, 2015 Schwan, R., y Fleet, G.

[6] https://www.dinero.com/edicion-impresa/pais/articulo/industria-delcacao-colombiano-produce-record/251611

[7] Schwan, R., y Fleet, G. (2015). Cocoa and Coffee Fermentations (first). London

[8] WM. Paez Ramos tesis "Propuesta de mejora del proceso de transformación del cacao en APOMD para la disminución de su desperdicio”,Universidad de la Salle, Bogota, Colombia, 2017.

[9] Ramírez Sulvarán, Jesús ARTuro AND Sigarroa Rieche, Alina KATIL AND DEl VAlle VARGAS, Rómulo Alberto Characterization of cocoa (theobroma cacao l.) farming systems in the norte de santander department and assessment their sustainability,Revista Facultad Nacional de Agronomía Medellín; Vol. 67, núm. 1 (2014); 7177-7187 2248-7026 0304-2847;(2014) 